\title{
Interaction between Recrystallization and Precipitation during Multipass Rolling in a Low Carbon Niobium Microalloyed Steel
}

\author{
R. ABAD, A. I. FERNÁNDEZ, B. LÓPEZ and J. M. RODRIGUEZ-IBABE \\ CEIT and ESI (Univ. of Navarra) Po de M. Lardizábal 15, E-20018 Donostia-San Sebastián, Basque Country, Spain.
}

(Received on April 9, 2001; accepted in final form on June 22, 2001)

\begin{abstract}
The interaction between recrystallization and precipitation processes during multipass deformation has been analysed in terms of the non recrystallization temperature $\left(T_{n r}\right)$. Multipass torsion tests performed at continuous cooling conditions have been used for thermomechanical simulation. The effect of the passstrain and the initial austenite microstructure on the $T_{\mathrm{nr}}$ value have been investigated. Conventionally reheated austenite $\left(T_{\text {soak }}=1200-1250^{\circ} \mathrm{C}\right)$ and as-cast austenite, the latter simulated in the laboratory by reheating at very high temperatures $\left(T_{\text {soak }}=1400^{\circ} \mathrm{C}\right)$, have been considered. It was observed that at low pass-strains the retardation on recrystallization was mainly due to solute drag effects, while increasing the strain, precipitation induced by deformation was allowed to occur during the interpass interval leading to a drastic reduction of the softening reached between passes at temperatures below the $T_{\mathrm{nr}}$. The increment of the reheating temperature led to higher $T_{\mathrm{nr}}$ values, being this effect related to higher austenite supersaturation levels prior to deformation.
\end{abstract}

KEY WORDS: multipass deformation; recrystallization; strain induced precipitation; non recrystallization temperature $\left(T_{n r}\right)$.

\section{Introduction}

The determination of the non recrystallization temperature $\left(T_{\mathrm{nr}}\right)$ is a crucial step in designing controlled rolling schedules, because it determines the temperature below which strain is accumulated in the austenite (pancaking). In that case the ferrite grain size obtained after the $\gamma-\alpha$ transformation is reduced, comparing to that obtained from the recrystallized austenite microstructure resulting by deformation at temperatures above the $T_{\mathrm{nr}}$. This temperature is a result of the interaction between deformation, recrystallization and precipitation. The following two mechanisms have been proposed as responsible: the solute drag effect due to solute atoms and the pinning effect due to strain induced precipitates, the latter usually exerting the stronger effect. $^{1-4)}$ A method to determine the $T_{\mathrm{nr}}$ was developed by Jonas and co-workers, ${ }^{5,6)}$ based on multipass torsion tests perfomed under continuous cooling conditions. This kind of test has been widely used to simulate industrial hotrolling processes. Under these conditions, the $T_{\mathrm{nr}}$ is a function of process variables which include pass-strain and strain rate, pass temperature and interpass time which all of them have a great effect on microstructural development during the rolling process.

Other parameter that also affects the $T_{\mathrm{nr}}$ is the austenite condition prior to deformation. New technologies of steel production tend to integrate the rolling process with the continuous casting process accounting for economical advantages. However, the austenite microstructure prior to hot direct rolling can differ significantly from the as-reheated one in conventional hot rolling. ${ }^{7)}$ The as-cast austenite is characterised by a very large grain size $(\approx 1000 \mu \mathrm{m})$ comparing to the as-reheated austenite, ${ }^{8)}$ it is segregated and may be more highly supersaturated with respect to microalloying elements than reheated austenite. ${ }^{7}$ Both factors can affect recrystallization and precipitation kinetics, thus, it may be expected that its response to rolling may differ from that of reheated austenite.

In the present paper the recrystallization and precipitation kinetics of a $\mathrm{Nb}$-microalloyed steel during multipass deformation under continuous cooling conditions have been investigated. The interaction between recrystallization and precipitation is considered in terms of the $T_{\mathrm{nr}}$. This work involves the study of the influence of the pass-strain and the initial austenite microstructure on the $T_{\mathrm{nr}}$ value. Both reheated austenite $\left(T_{\text {soak }}=1200-1250^{\circ} \mathrm{C}\right)$ and as-cast austenite, the latter simulated in the laboratory by reheating at a very high temperature $\left(T_{\text {soak }}=1400^{\circ} \mathrm{C}\right)$, have been considered.

\section{Experimental Procedure}

The chemical composition of the steel studied was as expressed in $\mathrm{wt} \%, 0.1 \mathrm{C}, 0.31 \mathrm{Si}, 1.42 \mathrm{Mn}, 0.0053 \mathrm{~N}$ and $0.035 \mathrm{Nb}$. The tests were carried out using an computer controlled torsion machine. The specimens had a gage length of $17 \mathrm{~mm}$ and a diameter of $7.5 \mathrm{~mm}$. An induction furnace was used to heat the specimens. This allows to reach very high temperatures $\left(1400^{\circ} \mathrm{C}\right)$ in order to obtain the large initial austenite grain sizes characteristic of hot direct or 
charge rolling processes. Multipass torsion tests have been performed to determine the non recrystallization temperature $\left(T_{\mathrm{nr}}\right)$. Before deformation, the specimens were preheated for $15 \mathrm{~min}$ at temperatures of 1200,1250 and $1400^{\circ} \mathrm{C}$. In one test a longer soaking time, $30 \mathrm{~min}$, was used at the reheating temperature of $1200^{\circ} \mathrm{C}$.

After reheating, the specimens were deformed under multipass torsion tests performed at decreasing temperature in the range $1180-700^{\circ} \mathrm{C}$. The temperature decrement between passes was of $30^{\circ} \mathrm{C}$. The tests were carried out using different pass-strains in the range $(\varepsilon=0.1-0.4$, a pass strainrate of $1 \mathrm{~s}^{-1}$ and interpass times of $30 \mathrm{~s}$ (cooling rate of $1^{\circ} \mathrm{C} / \mathrm{s}$ ). In a particular test, the strain per pass, the strainrate and the interpass time were held constant. The non recrystallization temperature has been determined by using the method proposed by Jonas and co-workers. ${ }^{5,6)}$ Some specimens were quenched at different stages during deformation in order to check the evolution of the microstructure. These specimens were quenched after the $i$-th pass and allowing for the interpass time. The starting austenite grain size and that from those quenched specimens were quantified. All metallographic characterisation was performed at a section corresponding to 0.9 of the outside radius of the torsion specimen, known also as the sub-surface plane. ${ }^{9)}$ In a previous work a good correlation between metallographically measured recrystallized fraction on this section and the fractional softening quantified from double pass torsion tests was observed. ${ }^{10)}$ Double hit torsion technique was also employed in a previous work to determine the isothermal recrystallization kinetics of the present steel. ${ }^{11)}$

\section{Results}

\subsection{Determination of the Non Recrystallization Tem- perature $\left(T_{\mathrm{nr}}\right)$}

Figure 1 shows the typical stress-strain curves obtained in a 17-pass torsion test, corresponding in this case to a test carried out after reheating at $1200^{\circ} \mathrm{C}$ and using a strain per pass of 0.3 , strain-rate of $1 \mathrm{~s}^{-1}$ and interpass time of $30 \mathrm{~s}$. The increase in the stress as the temperature drops is clearly evident, as well as a greater tendency towards hardening after approximately pass 8 . On the other hand, after pass 14 a reduction in the level of stress can be observed, denoting the start of the $\gamma \rightarrow \alpha$ phase transformation.

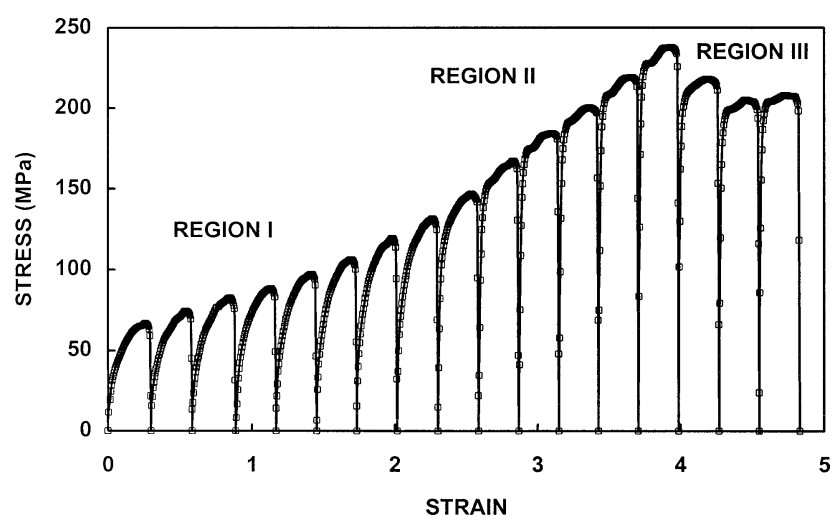

Fig. 1. Stress-strain curves obtained in a 17 pass torsion test corresponding to the following deformation conditions: $T_{\text {soak }}=1200^{\circ} \mathrm{C}(15 \mathrm{~min}), \varepsilon=0.3, t_{\text {ip }}=30 \mathrm{~s}$.
From Fig. 1 the mean flow stress (MFS) corresponding to each pass has been calculated by numerical integration and plotted against the inverse absolute temperature in Fig. 2. The MFS has been defined as the area under each stressstrain curve divided by the pass strain. Three different regions can be clearly distinguished in both, Figs. 1 and 2:

1) Region I: where it is supposed that complete recrystallization $(100 \%)$ between passes takes place and the stress increases from pass to pass are only due to temperature drop.

2) Region II: where recrystallization between passes is inhibited by strain induced precipitation. The stress increases more rapidly due to both, the temperature drop and the accumulation of strain.

3) Region III: corresponds to the austenite-ferrite region. The stress reduction results from the start of the transformation of austenite to softer ferrite phase $\left(\mathrm{A}_{\mathrm{r} 3}\right.$ temperature).

Following the method developed by Jonas and co-workers $^{5,6)}$ the value of $T_{\mathrm{nr}}$ can be determined from the intersection between the regression lines of the points corresponding to regions I and II. By this procedure the non recrystallization temperatures corresponding to the different initial austenite microstructure and deformation conditions considered in the torsion tests were calculated.

Figure 3 shows the influence of the pass-strain and the reheating temperature on the non recrystallization temperature. A significant decrease of the $T_{\mathrm{nr}}$ (about $60^{\circ} \mathrm{C}$ ) is observed when the pass strain increases from 0.1 to 0.2 . However, in the range of pass-strains between 0.2 and 0.4

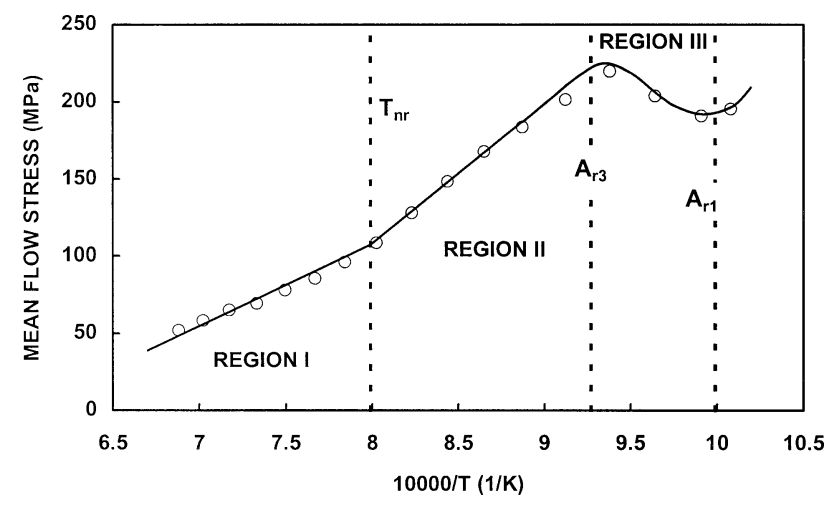

Fig. 2. Mean flow stress against inverse absolute temperature.

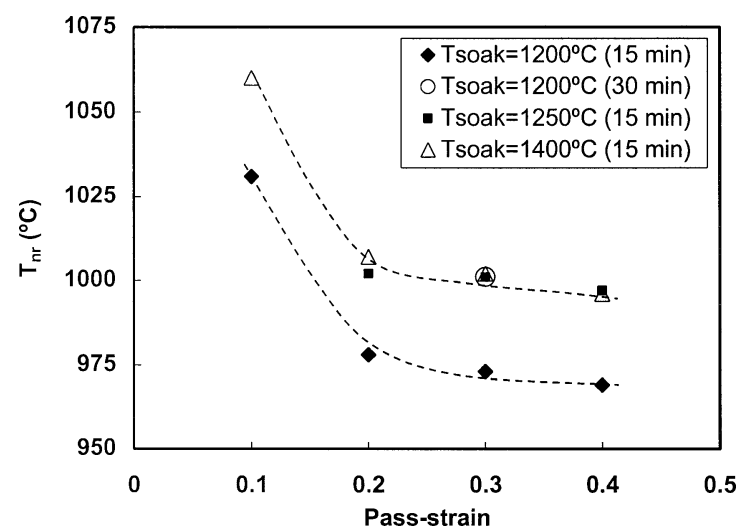

Fig. 3. Dependence of $T_{\mathrm{nr}}$ on pass strain for different reheating conditions. 

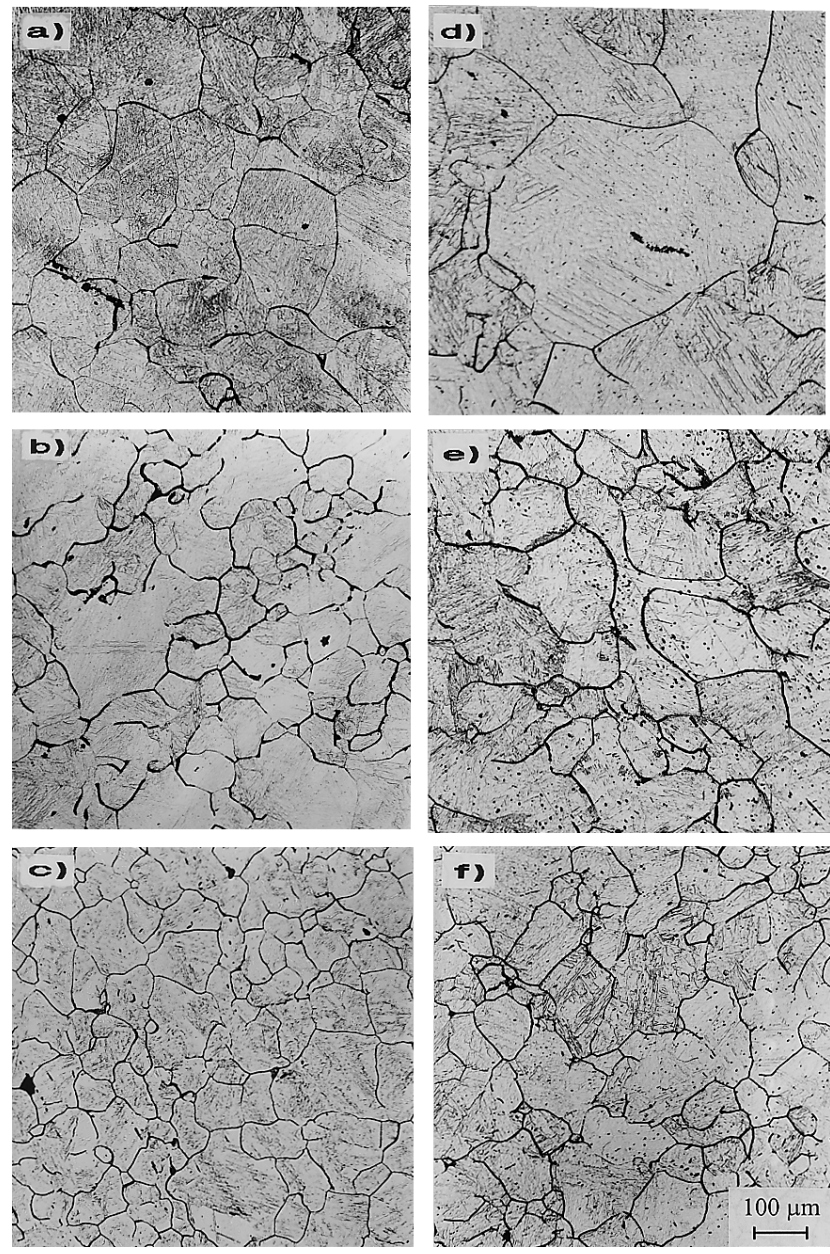

Fig. 4. Evolution of austenite microstructure during deformation for both reheating conditions: $T_{\text {soak }}=1200^{\circ} \mathrm{C}$, after a) $2^{\circ}$ pass $+30 \mathrm{~s}$, b) $4^{\circ}$ pass $+30 \mathrm{~s}$, c) $7^{\circ}$ pass $+30 \mathrm{~s}$; $T_{\text {soak }}$ $1400^{\circ} \mathrm{C}$, after d) $2^{\circ}$ pass $+30 \mathrm{~s}$, e) $4^{\circ}$ pass $+30 \mathrm{~s}$, f) $6^{\circ}$ pass $+30 \mathrm{~s}$.

the $T_{\mathrm{nr}}$ decreases slightly with increasing strain.

From the figure it is clearly seen that increasing the reheating temperature from 1200 to $1250^{\circ} \mathrm{C}$, the $T_{\mathrm{nr}}$ increases about $30^{\circ} \mathrm{C}$ for all strains. However, a further increase of the reheating temperature from 1250 to $1400^{\circ} \mathrm{C}$ does not produce any additional increment of the $T_{\mathrm{nr}}$. It is also observed that increasing the soaking time from 15 to $30 \mathrm{~min}$ at $1200^{\circ} \mathrm{C}$, increases the $T_{\mathrm{nr}}$ about $30^{\circ} \mathrm{C}$, reaching a similar value to that obtained at the higher reheating temperatures.

\subsection{Microstructural Evolution}

The initial austenite microstructure resulting from the reheating treatment has been characterized by optical metallography. After reheating at $1400^{\circ} \mathrm{C}$ a very coarse austenite microstructure is obtained, with a mean grain size of 806 $\mu \mathrm{m}$ comparing to the size of $129 \mu \mathrm{m}$ obtained after soaking at $1200^{\circ} \mathrm{C}$.

Figure 4 shows several micrographs of the microstructure evolution observed in specimens quenched at different stages during multipass deformation, in tests performed after reheating at 1200 and $1400^{\circ} \mathrm{C}$, and corresponding to a strain per pass of $\varepsilon=0.2$. Figures 4(c) and 4(f) show the microstructure observed just before the $T_{\mathrm{nr}}$. From the figure it is evident that, independently of the initial austenite grain size, after several passes the microstructures become simi- lar. The successive recrystallizations between passes gradually reduce the grain size and, when the $T_{\mathrm{nr}}$ is reached, it is observed in this case that the austenite grain size at that moment has practically no relation to the original one.

\section{Discussion}

\subsection{Modelling Static Recrystallization for Multipass Tests}

The evolution of the austenite microstructure after each deformation pass has been modelled. It must be pointed out that in the pass-strain range used in the present work dynamic recrystallization is not expected to occur for this steel, ${ }^{12)}$ thus, only static recrystallization has been considered. The progress of recrystallization can be represented according to the Avrami equation, using an exponent $n=1^{11)}$

$$
X=1-\exp \left[-0.693 \cdot\left(\frac{t}{t_{0.5 X}}\right)^{n}\right] .
$$

where $X$ is the recrystallized fraction, $t$ is the time (s), and $t_{0.5 X}$ is the time for $50 \%$ recrystallization. In a previous work the following equation, applicable to $\mathrm{Nb}, \mathrm{Ti}$ and $\mathrm{Nb}-$ Ti microalloyed steels over a wide range of initial austenite grain sizes and deformations, was developed to calculate the $50 \%$ recrystallization time $\left(t_{0.5 X}\right)^{11)}$ :

$$
\begin{aligned}
t_{0.5 X}= & 9.92 \times 10^{-11} D_{\mathrm{o}} \varepsilon^{-5.6 D_{\mathrm{o}}^{-0.15}} \dot{\varepsilon}^{-0.53} \exp \left(\frac{180000}{R T}\right) \\
& \times \exp \left[\left(\frac{275000}{T}-185\right) \cdot([\mathrm{Nb}]+0.374[\mathrm{Ti}])\right] \ldots
\end{aligned}
$$

where $D_{\mathrm{o}}$ represents the initial austenite grain size, $\varepsilon$ and $\dot{\varepsilon}$ are the applied strain and strain-rate respectively, $T$ is the deformation temperature and $[\mathrm{Nb}]$ and [Ti] represent the niobium and titanium $\mathrm{wt} \%$ concentrations in solution. This equation takes into account the retardation that microalloying elements in solution can produce on recrystallization time. $[\mathrm{Nb}]$ has been calculated using the solubility product equation proposed by Irvine et $a l .{ }^{13)}$ :

$$
\log [\mathrm{Nb}][\mathrm{C}+12 \mathrm{~N} / 14]=2.26-6770 / T
$$

Equations (1) and (2) were obtained for isothermal conditions, however, during multipass deformation the temperature decreases continuously. In those cases, the additivity rule is found to be very useful in the application of isothermal models for recrystallization to continuous cooling conditions. ${ }^{14)}$ The cooling curve is divided into increments of $\Delta t=0.01 \mathrm{~s}$ and the temperature drop for each step can be calculated as $\Delta T=\Delta t \cdot v$, being $v$ the cooling rate. If the accumulated recrystallized fraction at the end of an interval of temperature $T_{j}$ is $X_{j}$, the recrystallized fraction at the end of an interval of temperature $T_{j+1}\left(T_{j+1}<T_{j}\right)$ is calculated by first determining the "equivalent time" $t$ needed to reach a recrystallized fraction of $X_{j}$ during the isothermal annealing at $T_{j+1}$. The real recrystallized fraction at $T_{j+1}$ is calculated as: 


$$
X_{j+1}(\Delta t)=X_{j+1}(\Delta t+t)-X_{j+1}(t)
$$

The recrystallized fraction is calculated and added from interval to interval. By adding the holding time for each increment, the time necessary to obtain a certain recrystallized fraction can also be calculated.

The recrystallized grain size after the $i$-th pass is related to the previous grain size $\left(d_{i-1}\right)$ by an expression of the type $^{15)}$ :

$$
d_{i}=K d_{i-1}^{m} \varepsilon_{i}^{-p}
$$

where $K, m$ and $p$ are material dependent constants. ${ }^{5,15,16)}$ In the present work these coefficients have been adjusted to give the best fit with the experimental data of grain sizes measured on the specimens quenched at different stages during deformation (see Figs. 4(a) and 4(e)). The resulting values are $K=1.4, m=0.56$ and $p=1$ and they are in the range of those reported for $\mathrm{C}-\mathrm{Mn}$ and $\mathrm{C}-\mathrm{Mn}-\mathrm{Nb}$ steels. $^{5,15,16)}$

Following complete static recrystallization, the equiaxed austenite microstructure can coarsen by grain growth. The equation proposed by Hodgson and Gibbs ${ }^{17)}$ to express the kinetics of grain growth after recrystallization in $\mathrm{Nb}$-steels has been considered:

$$
D^{4.5}=d_{\text {rex }}^{4.5}+4.1 \times 10^{23} t_{\mathrm{q}} \exp \left(-\frac{435000}{R T}\right) \ldots \ldots .
$$

where $d_{\text {rex }}$ is the fully recrystallized grain size $(\mu \mathrm{m})$, and $t_{\mathrm{q}}$ is the time after complete recrystallization, assumed as $95 \%$ recrystallized fraction, $\left(t_{\mathrm{q}}=t_{\mathrm{ip}}-t_{0.95 X}\right.$, being $t_{\mathrm{ip}}$ the interpass time).

If the time between passes is not long enough to complete recrystallization, it is possible to have partial recrystallization after a pass strain $\varepsilon_{i}$. This introduces a mixed microstructure before the next pass of deformation $\varepsilon_{i+1}$. In this work, to take this into account the "uniform softening method"18) is used, assuming a single average microstructure with an effective strain after pass $(i+1)$ as follows:

$$
\varepsilon_{\mathrm{eff}}=\varepsilon_{i+1}+\lambda\left(1-X_{i}\right) \varepsilon_{i} \text { for } X_{i}>0.1
$$

where $\lambda$ is a constant which is taken as 0.5 for $\mathrm{Nb}$ steels ${ }^{19)}$ and $X_{i}$ is the recrystallized fraction between passes $i\left(\varepsilon_{i}\right)$ and $i+1\left(\varepsilon_{i+1}\right)$. In this method the partially recrystallized microstructure is described by an average grain size. Different expressions have been proposed to calculate this grain size. ${ }^{18,20)}$ Some authors calculate a mean grain size by the application of the law of mixtures, taking into account that the microstructure is a mixture of recrystallized and unrecrystallized grains. ${ }^{21,22)}$ Other authors utilise an average grain size equal to the full recrystallized grain size which would be obtained in the case of complete recrystallization. ${ }^{19,23)}$ In the present work the last approach has been adopted for modelling the evolution of the mixed microstructure when partial recrystallization is predicted to occur:

$$
\bar{d}=d_{\text {rex }}
$$

The microstructural changes have been determined by applying Eqs. (1) to (8) and the results are compared with experimental data of grain size in Fig. 5. From the figure it

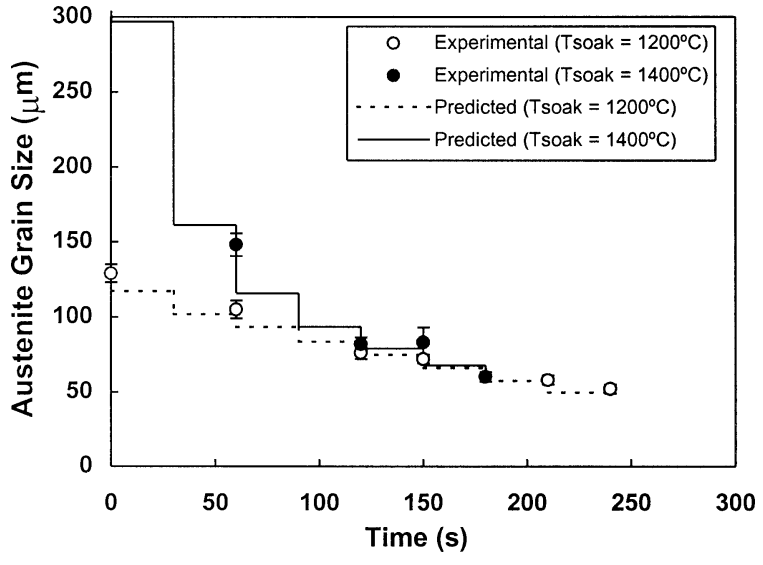

Fig. 5. Comparison between predicted and experimental data for the evolution of the austenite grain size during multipass deformation $\left(\varepsilon=0.2, \dot{\varepsilon}=1 \mathrm{~s}^{-1}, t_{\text {ip }}=30 \mathrm{~s}\right)$ after different reheating conditions $\left(T_{\text {soak }}=1200\right.$ and $\left.1400^{\circ} \mathrm{C}\right)$.

can be observed that for both reheating conditions the grain size calculations are in good agreement with the experimental values. It is also observed that, independently on the initial austenite microstructure, after several passes the austenite grain sizes converge, as it was observed previously in Fig. 4.

Other parameter determined by the model is the recrystallized fraction between passes. The results of the model have been compared to the values of the fractional softening which takes place between passes. The anisothermal interpass fractional softening (FS) is determined from the stress-strain curves obtained in multipass tests using the following equation ${ }^{24)}$ :

$$
\mathrm{FS}(\%)=\frac{\sigma_{\mathrm{m}}^{i}-\sigma_{\mathrm{y}}^{i+1} \frac{\sigma_{\mathrm{o}}^{i}}{\sigma_{\mathrm{o}}^{i+1}}}{\sigma_{\mathrm{m}}^{i}-\sigma_{\mathrm{o}}^{i}} \times 100
$$

where $\sigma_{\mathrm{m}}^{i}$ and $\sigma_{\mathrm{y}}^{i+1}$ are the maximum and the yield stresses for both, the $i$-th (at temperature $T_{i}$ ) and the $(i+1)$ st (at temperature $\left.T_{i}+1\right)$ passes respectively, while $\sigma_{\mathrm{o}}^{i}$ and $\sigma_{\mathrm{o}}^{i+1}$ are the yield stresses of a fully recrystallized material for the $i$ th and $(i+1)$ st passes. The yield stresses are determined by the $2 \%$ offset method. In a previous work a nearly linear relationship was observed between the softening calculated by this method and the metallographic measured recrystallized fraction. ${ }^{10)} \sigma_{\mathrm{m}}^{i}$ and $\sigma_{\mathrm{y}}^{i+1}$ are derived from the pass-topass flow curves such as those shown in Fig. 1, while $\sigma_{\mathrm{o}}^{i}$ and $\sigma_{\mathrm{o}}^{i+1}$ are determined from the following relationship which has been derived from the values of the yield stresses measured in the stress-strain curves corresponding to the range of complete recrystallization:

$$
\sigma_{\mathrm{o}}(\mathrm{MPa})=-203+352 \frac{1000}{T}
$$

Figures 6 and 7 show the values of fractional softening calculated using Eqs. (9) and (10) and those predicted by the recrystallization model, plotted against the inverse absolute mean temperature corresponding to the pass interval, for reheating conditions of 1200 and $1400^{\circ} \mathrm{C}$, respectively.

There is reasonable agreement between measured and 


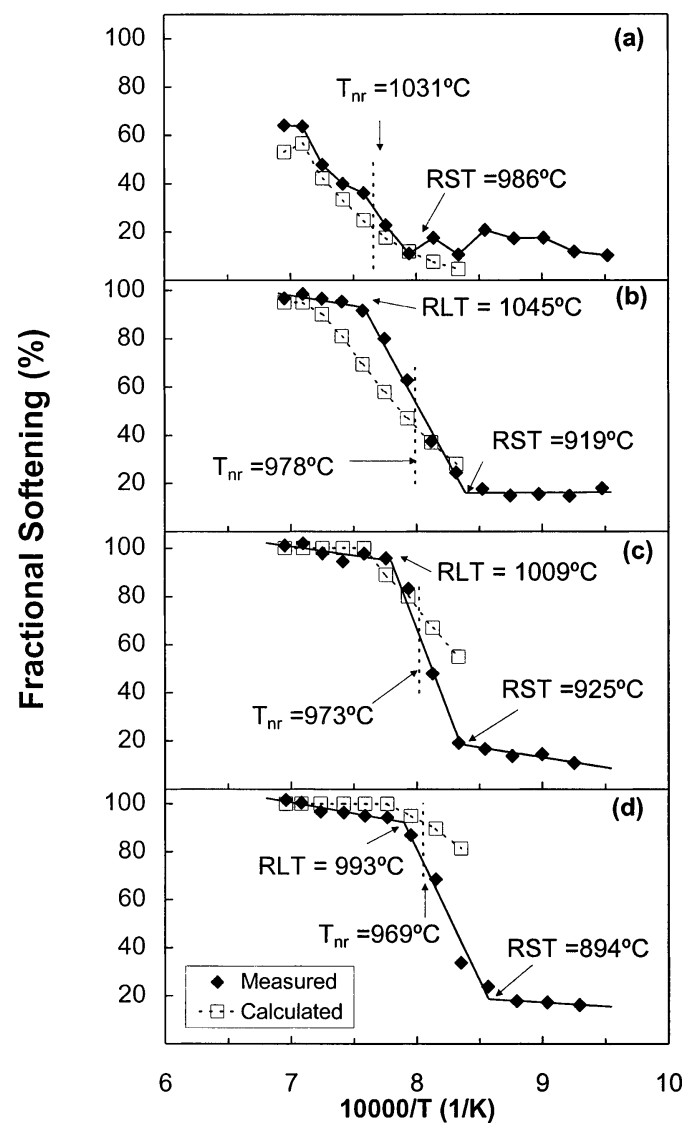

Fig. 6. Comparison between the measured fractional softening (FS) and the values predicted by the recrystallization model plotted against the mean interpass temperature for soak at $1200^{\circ} \mathrm{C}$ and pass-strains of: a) $\varepsilon=0.1$, b) $\varepsilon=0.2$, c) $\varepsilon=0.3$, d) $\varepsilon=0.4$.

predicted values of softening for pass-strains of $\varepsilon=0.3$ and 0.4 in the range of temperatures above the $T_{\mathrm{nr}}$ (indicated in the figures), while at temperatures below this, predicted values are higher than the measured ones. In the range of low pass-strains $(\varepsilon=0.1-0.2)$ the model predicts a faster decrease of the softening ratio with the temperature reduction than that observed experimentally.

On the other hand, it is clearly evident that the softening behaviour is dependent on the pass-strain. It is observed that for the lowest pass-strain of $\varepsilon=0.1$, the amount of softening after the initial passes is very small, between 50 and $65 \%$, and decreases rapidly when decreasing the temperature. In this case, when the $T_{\mathrm{nr}}$ is reached the amount of softening is about $35 \%$. However, as the pass-strain increases the amount of softening is higher, close to $100 \%$ at initial passes, although it also decreases when the temperature drops.

Radovic et al. ${ }^{25)}$ approximate the FS(\%) vs. 1/T plots by three linear segments, which intersect at temperatures denoted by them as $T_{\mathrm{rl}}$ and $T_{\mathrm{rs}}$. These temperatures can be considered as the recrystallization limit (RLT) and recrystallization stop (RST) temperatures proposed by Dutta and Sellars. ${ }^{26)}$ RLT is defined as the lowest temperature above which recrystallization between passes is complete ( 85 or $95 \%$ recrystallization criteria have been used $^{26)}$ ) and RST represents the highest temperature at which recrystallization is completely absent (usually the criteria of $5 \%$ recrystallized fraction is considered). These temperatures have

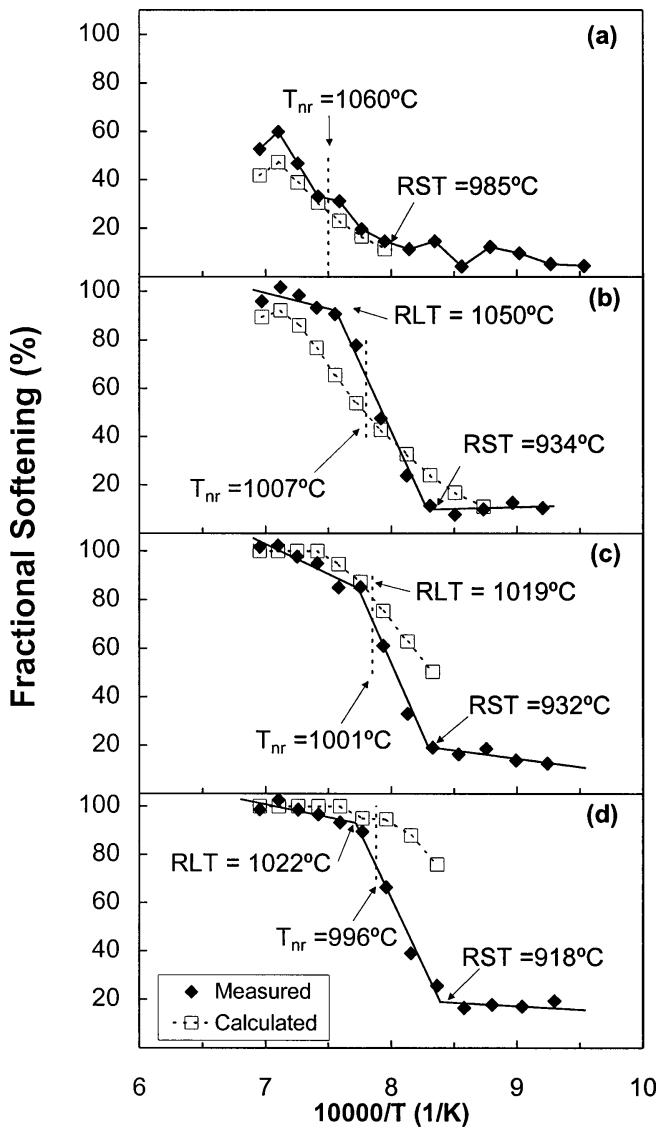

Fig. 7. Comparison between measured fractional softening (FS) and the values predicted by recrystallization model plotted against the mean interpass temperature for soak at $1400^{\circ} \mathrm{C}$ and pass-strains of: a) $\varepsilon=0.1$, b) $\varepsilon=0.2$, c) $\varepsilon=0.3$, d) $\varepsilon=0.4$.

been indicated in Figs. 6 and 7 as well as the determined values of $T_{\mathrm{nr}}$ and are listed in Table 1. From the figures and the table it is observed that the $T_{\mathrm{nr}}$ values are located always between RLT and RST temperatures. It is also observed that the RLT temperatures correspond approximately to softening fractions between 85 and $95 \%$. At temperatures below the RST the softening fraction is always less than $20 \%$.

The amount of softening reached after the pass previous to the $T_{\mathrm{nr}}$ is also indicated in Table 1 and it can be observed that it varies with the strain. The softening increases from 63 to $87 \%$, for the case of reheating at $1200^{\circ} \mathrm{C}$, and from 78 to $89 \%$, for the case of $1400^{\circ} \mathrm{C}$, when the strain increases from $\varepsilon=0.2$ to 0.4 . Medina ${ }^{27)}$ also predicted in the case of a $\mathrm{Nb}-\mathrm{V}-\mathrm{Ti}$ microalloyed steel that when the $T_{\mathrm{nr}}$ was reached the austenite was not totally recrystallized, with fractions of about 60 and $46 \%$ in torsion tests carried out using a pass-strain of $\varepsilon=0.26$ and interpass times of 40 and $90 \mathrm{~s}$ respectively. A similar effect was observed by Radovic et al. in the case of increasing the interpass time for a constant pass-strain. ${ }^{25)}$ From the previous results it is evident that $T_{\mathrm{nr}}$ does not exactly represent the temperature before which the recrystallization between passes is complete, but when reaching this temperature the fraction recrystallized could be smaller, depending on the pass strain and the interpass time. The higher the value of these parameters the higher the amount of softening when $T_{\mathrm{nr}}$ is reached.

On the other side, for pass-strains of $\varepsilon=0.3$ and 0.4 at 
Table 1. Values of the critical temperatures and the corresponding softening fractions reached after the previous pass to the $T_{\mathrm{nr}}$.

\begin{tabular}{|c|c|c|c|c|c|}
\hline$T_{\text {reheating }}\left({ }^{\circ} \mathrm{C}\right)$ & Pass-strain & RLT $\left({ }^{\circ} \mathrm{C}\right)$ & $\left.\mathrm{T}_{\text {nr }}{ }^{\circ} \mathrm{C}\right)$ & RST $\left({ }^{\circ} \mathrm{C}\right)$ & FS (\%) \\
\hline \multirow{7}{*}{1200} & 0.1 & - & 1031 & 986 & 36 \\
\cline { 2 - 6 } & 0.2 & 1045 & 978 & 919 & 63 \\
\cline { 2 - 6 } & 0.3 & 1009 & 973 & 925 & 83 \\
\cline { 2 - 6 } & 0.4 & 993 & 969 & 894 & 87 \\
\hline \multirow{3}{*}{1400} & 0.1 & - & 1060 & 985 & 33 \\
\cline { 2 - 7 } & 0.2 & 1050 & 1007 & 934 & 78 \\
\cline { 2 - 7 } & 0.3 & 1019 & 1001 & 932 & 85 \\
\cline { 2 - 7 } & 0.4 & 1022 & 996 & 918 & 89 \\
\hline
\end{tabular}

temperatures below the $T_{\mathrm{nr}}$ the values of softening predicted by the recrystallization model are above the measured ones. This behaviour is related to the interaction between strain induced precipitation phenomena taking place during the interpass interval at this temperature range and recrystallization. ${ }^{28)}$ Owing to the effect of the precipitates, the softening reached between consecutive passes is less than what would be expected by the recrystallization process itself. This suggests, that in this case the $T_{\mathrm{nr}}$ represents the temperature at which strain induced precipitation starts.

\subsection{Modelling Strain Induced Precipitation for Multi- pass Tests}

Precipitation kinetics has been determined using the equation proposed by Dutta and Sellars. ${ }^{26)}$ These authors modelled the interaction between strain and precipitation to predict the temperature at which, for a given strain, sufficient precipitation occurred quickly enough to stop recrystallization. The time required for $5 \%$ precipitation is represented by the following equation:

$$
t_{0.05 \mathrm{P}}=A[\mathrm{Nb}]^{-1} \varepsilon^{-1} Z^{-0.5} \exp \left(\frac{270000}{R T}\right) \exp \left(\frac{B}{T^{3}\left(\ln k_{\mathrm{s}}\right)^{2}}\right)
$$

where $Z$ is the Zener-Hollomon parameter, $Z=$ $\dot{\varepsilon} \exp \left(Q_{\text {def }} / R T\right)$, with $\dot{\varepsilon}$ the strain-rate and $Q_{\text {def }}$ the activation energy for deformation. Dutta and Sellars used a value of $Q_{\text {def }}=400 \mathrm{~kJ} / \mathrm{mol}$. The constants $A$ and $B$ were calculated to fit experimental data of $\mathrm{Nb}$-bearing steels and the mean values of $A=3 \times 10^{-6}$ and $B=2.5 \times 10^{10}$ were found to give accurate predictions for conventionally reheated austenite (up to about $\left.1250{ }^{\circ} \mathrm{C}\right){ }^{26)} k_{\mathrm{s}}$ represents the supersaturation ratio at the temperature $T$, defined as the ratio of the actual amount of $[\mathrm{Nb}][\mathrm{C}+12 / 14 \mathrm{~N}]$ in solution to the equilibrium amount which is calculated using the solubility product equation proposed by Irvine et al. ${ }^{13)}$ (Eq. (3)).

Equation (11) was derived for isothermal conditions, and the additivity rule has been used again to predict the continuous cooling behaviour. The time required for $5 \%$ precipitation after each pass is calculated using the relation ${ }^{14)}$ :

$$
\sum_{T_{i}}^{T} \frac{\Delta t}{t_{0.05 \mathrm{P}}\left(T_{j}\right)}=1
$$

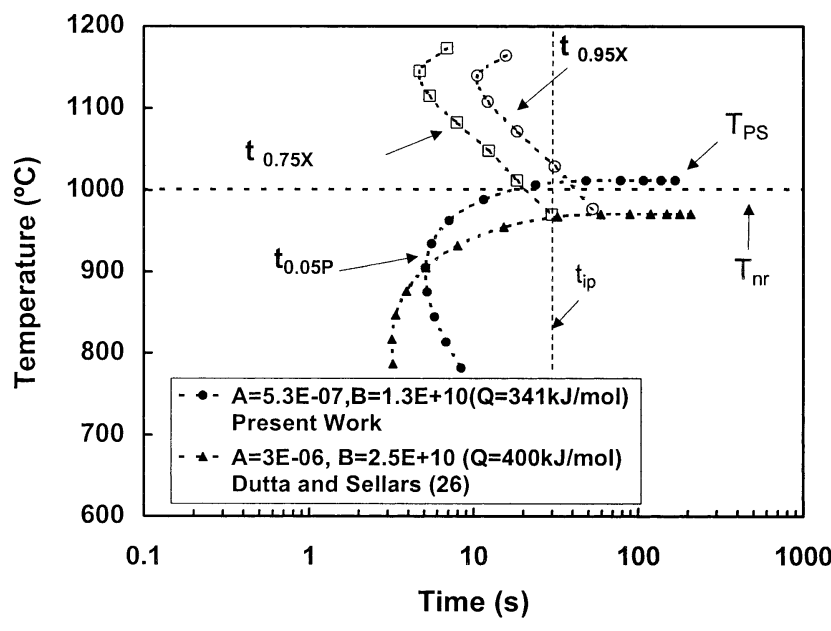

Fig. 8. Calculated strain induced precipitation start times and times for 75 and $95 \%$ recrystallized fractions $\left(T_{\text {soak }}=\right.$ $1400^{\circ} \mathrm{C}, \varepsilon=0.3, t_{\text {ip }}=30 \mathrm{~s}$ ).

where $t_{0.05 \mathrm{P}}\left(T_{j}\right)$ is the time for $5 \%$ precipitation at the time interval of temperature $T_{j}$, and $T_{i}$ is the deformation temperature for the $i$-th pass. The precipitation start time is evaluated after each pass from the time when the summatorial $\Delta t / t_{0.05 \mathrm{P}}\left(T_{j}\right)$ reaches unity.

The times predicted by Eq. (11) using the values of $A, B$ and $Q_{\text {def }}$ proposed by Dutta and Sellars are shown in Fig. 8, for the case of a reheating temperature of $1400^{\circ} \mathrm{C}$ and passstrain of 0.3 . The points represent the times and temperatures that must be reached after each pass for $5 \%$ precipitation to take place. In the same figure the times calculated by the recrystallization model (Eqs. (1) to (8)) to reach a 75 and $95 \%$ recrystallized fraction after each pass have been plotted. It must be pointed out that the kinetics of recrystallization and precipitation are modeled separately.

From this figure it is predicted that, with the constants proposed by Dutta and Sellars, it is necessary to go to temperatures as low as $\sim 970^{\circ} \mathrm{C}$ (which corresponds to the eighth pass) so that a sufficiently short precipitation time avoids recrystallization during the interpasss interval. However, the value of $T_{\mathrm{nr}}$, which is around $1000^{\circ} \mathrm{C}$, indicates that precipitation interacts with recrystallization at higher temperatures. This means that the kinetics of strain induced precipitation should be accelerated in order to produce better agreement with experimental results. The same behaviour was observed for $\varepsilon=0.2$ and $\varepsilon=0.4$ pass-strains. 
An acceleration of the precipitation kinetics was also reported by Prietsner et al. ${ }^{29)}$ in order to extent the applicability of the Dutta and Sellars model to both as-cast and reheated austenite.

For the present steel a value of $Q_{\text {def }}=341 \mathrm{~kJ} / \mathrm{mol}$ was determined previously, ${ }^{30)}$ which must be considered in the calculation of the precipitation times. Taking it into account, the following new values of the constants have been calculated for a better fit with the experimental $T_{\mathrm{nr}}$ observations, $A=5.3 \times 10^{-7}$ and $B=1.3 \times 10^{10}$. The calculated precipitation times are shown in Fig. 8. The precipitation start times calculated from Eq. (11), by using these values of the constants and the activation energy, show reasonable agreement with the isothermal strain induced precipitation data reported by Kang et al. ${ }^{31)}$ for a $\mathrm{Nb}$-steel with similar composition to the present one. In Fig. 8 it can be seen that after the seventh pass (just below the $T_{\mathrm{nr}}$ ) precipitation starts in approximately $11 \mathrm{~s}$, and the time required for $75 \%$ recrystallization is close to $30 \mathrm{~s}$. Therefore a significant amount of precipitation is expected to occur after the seventh pass, which is in accordance with the reduction of fractional softening observed in this interval in comparison with the recrystallization model prediction (see Fig. 7).

From Fig. 8 it can be concluded that a minimum temperature is required for precipitation to start at the current deformation and cooling conditions. This temperature can be considered as the continuous cooling precipitation start temperature $\left(T_{\mathrm{PS}}\right)$ defined by Sun et al. ${ }^{32)}$ This temperature for a constant pass-strain will be dependent on the interpass time, leading to higher values as the interpass time rises, due to the increase of the time available for precipitation. According to these authors, for a pass-strain of $\varepsilon=0.3$ and in the range of medium interpass times (between 20 and $50 \mathrm{~s}$ ), when precipitation is the controlling mechanism in the retardation of recrystallization, there is a similarity between $T_{\mathrm{nr}}$ and $T_{\mathrm{PS}}$. Following that, it can be thought that the similarity found between the experimental value of $T_{\mathrm{nr}}$ and the calculated $T_{\mathrm{PS}}$ in Fig. 8 helps to validate the precipitation model.

\subsection{Effect of Pass-strain on the $\boldsymbol{T}_{\mathrm{nr}}$}

From Fig. 3 it has been observed that the $T_{\mathrm{nr}}$ tends to decrease when increasing the pass-strain, especially in the range of low strain values (from 0.1 to 0.2 ). This dependence is in good agreement with published data and is related to several factors contributing to extend recrystallization with increasing strain. ${ }^{5)}$ In microalloyed steels, the $T_{\mathrm{nr}}$ is mainly related to the interaction between recrystallization and precipitation. ${ }^{26,33)}$ Moreover, Bai and Jonas ${ }^{5)}$ demonstrated that even in absence of precipitation, a $T_{\mathrm{nr}}$ is obtained in the case of short interpass times, as a result of the retardation of recrystallization by solute drag effect.

The kinetics of recrystallization and precipitation are strongly dependent on strain. It is well known that the time required to reach a $50 \%$ recrystallized fraction $\left(t_{0.5 X}\right)$ decreases as the strain increases, following a dependence of the type $t_{0.5 X} \propto \varepsilon^{-m}$. For the present steel, a dependence of $m$ on initial austenite grain size was reported in a previous work as indicated in Eq. (2), ${ }^{11)}$ predicting that the coefficient $m$ varies between 2 and 4 in the austenite grain size range of $20-1000 \mu \mathrm{m}$. These values are in the range of

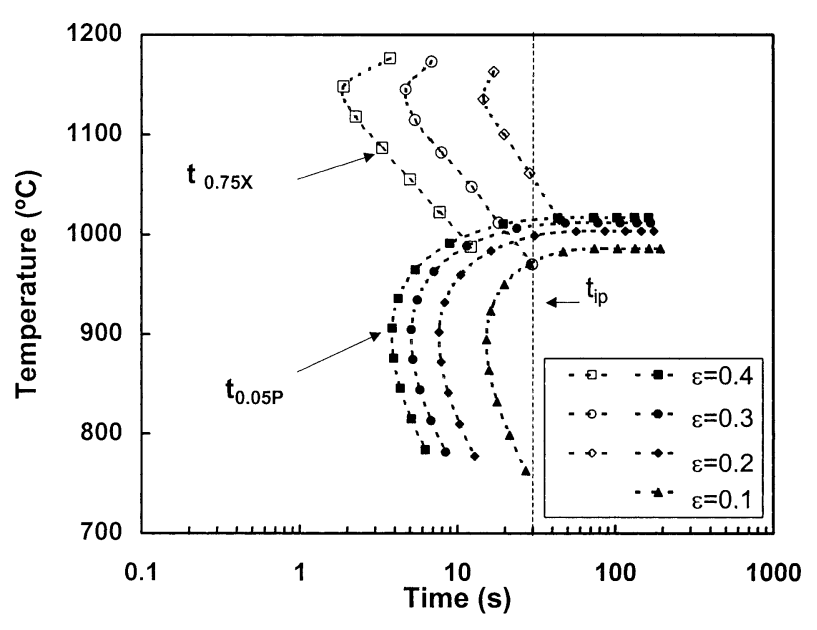

Fig. 9. Effect of strain on recrystallization and precipitation kinetics $\left(T_{\text {soak }}=1400^{\circ} \mathrm{C}, t_{\text {ip }}=30 \mathrm{~s}\right)$.

those suggested for the $m$ coefficient in the literature. ${ }^{15,34-36)}$ The strain induced precipitation start time also diminishes with increasing the strain, though precipitation kinetics are less sensitive to strain than recrystallization kinetics. A relationship of the type $t_{0.05 \mathrm{P}} \propto \varepsilon^{-1}$ has been reported for $\mathrm{Nb}$ microalloyed steels ${ }^{26)}$ and this dependence has been adopted in the precipitation equation Eq. (11). In consequence, the behaviour observed in Fig. 3 for the $T_{\mathrm{nr}}$ should be the result of the effect of strain on both processes.

Figure 9 shows the influence of strain on the recrystallization (75\%) and precipitation (5\%) kinetics calculated with the present equations (Eqs. (1) to (12)). From the figure it is observed that for a pass-strain of $\varepsilon=0.1$ precipitation is predicted to occur below $\sim 970^{\circ} \mathrm{C}$ in the interpass interval between the 8 th and the 9 th passes. However, for this low strain the recrystallization times are very long, outside the range shown in Fig. 9, always longer than the interpass time and leading to the occurrence of partial recrystallization for the whole deformation range (see Fig. 7). This indicates that solute drag would be, in this case, the controlling mechanism in retarding recrystallization and the $T_{\mathrm{nr}}$ is determined by the amount of softening that can be reached during the interpass interval as the temperature drops, excluding any interaction with precipitation.

At medium strains $(\varepsilon=0.2)$ precipitation is predicted to occur inside the interpass interval at temperatures below $\sim 1000^{\circ} \mathrm{C}$ (the seventh pass), just below the determined $T_{\mathrm{nr}}$. In this case the recrystallization model predicts that at temperatures below $1060^{\circ} \mathrm{C}$ (the 5th pass), the time required to reach a $75 \%$ recrystallization is longer than the interpass time. This means that precipitation would take place in a partially recrystallized austenite. However, from Fig. 7 the experimentally measured softening fractions denote a higher extent of recrystallization than that predicted from the model. As it can be seen in Fig. 7 the amount of softening reached after the pass given at $1030^{\circ} \mathrm{C}$ (6th pass) is $78 \%$, being necessary to go to temperatures below the $T_{\mathrm{nr}}$ $\left(1007^{\circ} \mathrm{C}\right)$ to have an important softening reduction.

When the pass-strains are 0.3 and 0.4 , after the seventh pass, just below the $T_{\mathrm{nr}}$, precipitation start times became significantly shorter than the times required for $75 \%$ recrystallization. This means that precipitation can take place and thus retard recrystallization, explaining the significant 
softening reduction observed after this pass in Fig. 7. In this strain range, the retardation of recrystallization starts at a temperature which is close to the calculated precipitation start temperature $\left(T_{\mathrm{PS}}\right)$ (see Fig. 8 ), indicating that precipitation is the controlling mechanism.

The previous results denote that the non recrystallization temperature determined in this way, for $\varepsilon>0.2$, represents the temperature below which strain induced precipitation starts to take place during the interpass interval, independently of the amount of recrystallization reached at this point, which means that above this temperature complete recrystallization between passes does not necessarily occur.

Another important feature that can be concluded from the present work is that the effect of pass-strain on the $T_{\mathrm{nr}}$ temperature, at least in the range of medium interpass times as that used here, is quite similar to the effect of the interpass time reported by Bai and Jonas. ${ }^{5)}$ These authors observed that at short interpass times the retardation of recrystallization was only due to solute drag, but increasing the interpass time, strain induced precipitation took place and strongly retarded recrystallization, rising the $T_{\mathrm{nr}}$. Similarly, with respect to the influence of the strain, it is observed that for low strains, the $T_{\mathrm{nr}}$ is only due to solute drag effects, however increasing the strain, precipitation is allowed to take place during the interpass interval, producing a strong delay on recrystallization.

\subsection{Effect of Reheating Temperature on the $\boldsymbol{T}_{\mathrm{nr}}$}

From Fig. 3 it is also observed that increasing the reheating temperature from 1200 to 1250 or $1400^{\circ} \mathrm{C}$, the $T_{\mathrm{nr}}$ increases about $30^{\circ} \mathrm{C}$ for all tested strain range. There could be several reasons for this increase. First, as the reheating temperature rises the austenite grain size prior to deformation increases. It is well known that austenite grain size coarsening difficulties recrystallization and a retarding effect can be produced in this way, rising the $T_{\mathrm{nr}}$ temperature. However, in the present tests several passes are applied in the recrystallization region and, as mentioned before, when the $T_{\mathrm{nr}}$ is reached, the austenite grain size at that moment has practically no relation with the original grain size (see Fig. 4). Therefore, in this case the large austenite grain size obtained by the higher reheating temperature, cannot account for the increase of the $T_{\mathrm{nr}}$.

The non recrystallization temperature is related to solute drag effects of microalloying elements or is the result of the interaction between recrystallization and strain induced precipitation of carbonitrides during hot working. The occurrence of precipitation will depend on the supersaturation level reached when the temperature decreases during deformation after reheating. Increasing the reheating temperature, more particles will be dissolved during the soaking treatment, leading to higher supersaturation level and consequently, giving a larger driving force for precipitation to occur. As suggested by Gibbs et al., ${ }^{37)}$ the higher the microalloying solute supersaturation the higher the temperature at which strain induced precipitation can inhibit static recrystallization. In the case of solute drag being the main mechanism responsible for the retardation of recrystallization, increasing the amount of element in solution will enhance the drag effect. Thus the values of the $T_{\mathrm{nr}}$ will be increased in this way.

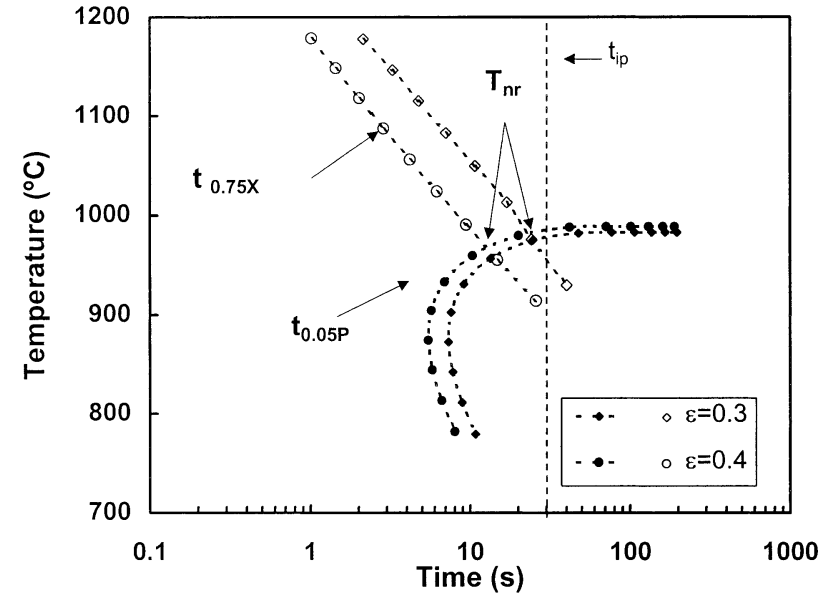

Fig. 10. Recrystallization and precipitation kinetics after soaking at $1200^{\circ} \mathrm{C}(15 \mathrm{~min})$ calculated assuming an amount of $\mathrm{Nb}$ in solution equal to $0.029 \%$.

Subsequently, it can be thought that the presence of more niobium in solution could be the reason of the increment of $T_{\text {nr }}$ observed when the reheating temperature increases from 1200 to $1250^{\circ} \mathrm{C}$. A further increase from 1250 to $1400^{\circ} \mathrm{C}$ does not produce any additional increase of the $T_{\mathrm{nr}}$, denoting that at these high temperatures probably all the niobium is already in solution. It is also observed that at $1200^{\circ} \mathrm{C}$ increasing the soaking time rises the $T_{\mathrm{nr}}$ to the level corresponding to higher temperatures. It can be argued that increasing the time more particles can be dissolved during the treatment, giving consequently a higher supersaturation level.

When Eq. (11) is applied to calculate the precipitation start times after reheating at $1200^{\circ} \mathrm{C}$, similar results to those for the case of reheating at $1400^{\circ} \mathrm{C}$ (precipitation kinetics shown in Fig. 9) are obtained. The amount of niobium present in solution and the supersaturation ratio $\left(k_{\mathrm{s}}\right)$ are calculated by applying the solubility product equation of Irvine et al. (Eq. (3)). This equation predicts for the composition of the present steel that in equilibrium conditions all niobium will be in solution at temperatures higher than $1168^{\circ} \mathrm{C}$. However, this may not be necessarily true in practice. In fact, it is observed that the $T_{\mathrm{nr}}$ values obtained after reheating at $1200^{\circ} \mathrm{C}$ during $15 \mathrm{~min}$ are about $30^{\circ} \mathrm{C}$ lower than those obtained after reheating at this temperature but longer times $(30 \mathrm{~min})$ or higher temperatures $(1250$, $1400^{\circ} \mathrm{C}$ ). This means that after 15 min soaking equilibrium conditions have probably not achieved.

From the experimental values of $T_{\mathrm{nr}}$ it is deduced that the precipitation (Eq. (11)) and recrystallization (Eq. (2)) times for the soaking treatment of $1200^{\circ} \mathrm{C}, 15 \mathrm{~min}$, should be calculated by using in the corresponding equations an amount of $\mathrm{Nb}$ in solution of $\approx 0.029 \%$. In Fig. 10 the predicted times for $5 \%$ precipitation and $75 \%$ recrystallization calculated in this way for the pass-strains of $\varepsilon=0.3$ and 0.4 are shown. The precipitation times became shorter than recrystallization times after $\sim 970^{\circ} \mathrm{C}$ (the eighth pass), just below the $T_{\mathrm{nr}}$. After this pass it can be observed in Fig. 6 that softening is reduced indicating that precipitation hardening is taking place. 


\subsection{Modelling the Non Recrystallization Temperature $\left(T_{\mathrm{nr}}\right)$}

The previous results suggest that a revision of the concept of $T_{\text {nr }}$, is required, mainly from the point of view of modelling this temperature. Bai and Jonas ${ }^{5)}$ considered that the $T_{\mathrm{nr}}$ could be predicted by the intersections of the $t_{0.05 \mathrm{P}}$ which represents the time required for $5 \%$ precipitation (precipitation start time), and $t_{0.95 X}$ curves, the last corresponding to a $95 \%$ recrystallization curve. The same criteria was used by Liu et al. ${ }^{22)}$ who also used multipass torsion tests to determine the $T_{\mathrm{nr}}$ and defined it as the temperature of the pass before which during the previous interpass interval the time for $5 \%$ precipitation became smaller or equal to the time for $95 \%$ recrystallization. This means that before the $T_{\text {nr }}$ defined in such manner, complete recrystallization between passes is reached, being in this case the value of the $T_{\mathrm{nr}}$ close to the RLT proposed by Dutta and Sellars. ${ }^{26)}$ However, as mentioned before, it has been observed that this situation can change depending on the interpass time and the pass-strain used. If the combination of pass-strain and interpass time assures that recrystallization can reach completion between passes, the only mechanism responsible for the retardation of recrystallization would be strain induced precipitation when it is allowed to occur during the interpass interval. In this case, before the $T_{\mathrm{nr}}$ is reached, the fraction recrystallized will be around $95 \%$, in coincidence with the criterion used by Bai and Jonas. ${ }^{5}$ On the contrary, in the range of short interpass times and/or low pass-strains, where recrystallization between passes cannot be completed, before reaching the $T_{\mathrm{nr}}$ there is partial recrystallization between passes. This difficulties accurate predictions of this temperature for these deformation conditions.

\section{Conclusions}

(1) By the application of the additivity rule to the equations derived at isothermal conditions, the recrystallization and precipitation kinetics of a $\mathrm{Nb}$-microalloyed steel during multipass deformation under continuous cooling have been obtained. This allows the study of the interaction between recrystallization and precipitation, and its influence on the non recrystallization temperature $\left(T_{\mathrm{nr}}\right)$.

(2) The variation of the $T_{\mathrm{nr}}$ with strain depends on the competition between solute drag effect and strain induced precipitation. At low pass-strains $(\varepsilon=0.1)$, the recrystallization of the austenite is controlled by the solute drag effect and the $T_{\mathrm{nr}}$ is determined by the amount of recrystallization that can be reached during the interpass interval without interaction with precipitation. However, increasing the strain $(\varepsilon>0.2)$ precipitation is able to occur during the interpass interval, producing a strong retardation on recrystallization when the temperature drops below the $T_{\mathrm{nr}}$. For this strainrange the $T_{\mathrm{nr}}$ represents the temperature below which strain induced precipitation starts to take place during the interpass interval.

(3) The amount of recrystallization reached in the interpass interval before the $T_{\mathrm{nr}}$ depends on the pass-strain. For a pass-strain of $\varepsilon=0.1$ the amount of softening calculated at this point is about $35 \%$, but increases to nearly $90 \%$ for a pass-strain of $\varepsilon=0.4$. This means that above the $T_{\mathrm{nr}}$ complete recrystallization between passes does not necessarily occur.

(4) Increasing the soaking temperature and permanence time, the $T_{\mathrm{nr}}$ increases. This increment is related to the enhancement of the drag effect exerted by elements in solution and the increase of the supersaturation level which enlarges the driving force needed for precipitation.

\section{Acknowledgements}

The authors thank the European Coal and Steel Community and the Spanish CICYT research programme (MAT95-1209-CE) for partial funding of the research.

\section{REFERENCES}

1) M. G. Akben, I. Weiss and J. J. Jonas: Acta Metall., 29 (1981), 111.

2) W. P. Sun, W. J. Liu and J. J. Jonas: Metall. Trans. A, 20 (1989), 2707.

3) J. G. Speer and S. S. Hansen: Metall. Trans. A, 20 (1989), 25.

4) O. Kwon and A. J. DeArdo: Acta Metall, 39 (1991), 529.

5) D. Q. Bai, S. Yue, W. P. Sun and J. J. Jonas: Metall. Trans. A, 24 (1993), 2151.

6) L. P. Karjalainen, T. M. Maccagno and J. J. Jonas: ISIJ Int., 35 (1995), 1523.

7) R. Priestner: Proc. of Int. Conf. Microalloying in Steels, ed. by J. M. Rodríguez-Ibabe et al., Trans. Tech. Publications, Switzerland, (1998), 95

8) C. A. Muojekwu, D. Q. Jin, I. V. Samarasekera and J. K. Brimacombe: Proc. of 37th MWSP Conf., Vol. 33, ISS, Warrendale, PA, (1996), 617.

9) G. Glover and C. M. Sellars: Metall. Trans. A, 3 (1972), 2271.

10) A. I. Fernández, B. López and J. M. Rodríguez-Ibabe: Scripta Mater., 40 (1999), 543.

11) A. I. Fernández, P. Uranga, B. López and J. M. Rodríguez-Ibabe: ISIJ Int., 40 (2000), 893.

12) A. I. Fernández, R. Abad, B. López and J. M. Rodríguez-Ibabe: Proc. of Int. Conf. Microalloying in Steels, ed. by J. M. Rodríguez-Ibabe et al., Trans. Tech. Publications, Switzerland, (1998), 135.

13) K. J. Irvine, F. B. Pickering and T. Gladman: J. Iron Steel Inst., 205 (1967), 161.

14) E. Scheil: Arch. Eisenhüttenwes., 12 (1935), 565.

15) C. M. Sellars: Proc. of Int. Conf. Hot Working and Forming Processes, ed. by C. M. Sellars and G. J. Davies, Met. Soc., London, (1980), 440.

16) J. H. Beynon and C. M. Sellars: ISIJ Int., 32 (1992), 359.

17) P. D. Hodgson and R. K. Gibbs: ISIJ Int., 32 (1992), 1329.

18) P. Choquet, A. Le Bon and Ch. Perdrix: Proc. of Int. Conf. on the Strength of Metals and Alloys, ICSMA 7, ed. by H. J. McQueen, J. P. Bailon, J. I. Dickson, J. J. Jonas and M. G. Abken, Vol. 2, Pergamon Press, New York, (1985), 1025.

19) Ch. Perdrix: Characteristic of Plastic Deformation of Metals During Hot Working, ECSC Report, No. 7210 EA/31. Institute de Recherches de la Siderurgie Francaise (IRSID), Paris, (1987).

20) J. H. Beynon, A. R. S. Ponter and C. M. Sellars: Proc. of Int. Conf. Modelling of Metall Forming Processes, eds. by J. L. Chenot and E. Oñate, Kluwer Academic Publishers, Dordrecht, (1988), 321.

21) C. Roucoules, S. Yue, and J. J. Jonas: 1st Int. Conf. of Modelling of Metal Rolling Processes, The Institute of Materials, London, (1993), 165.

22) X. Liu, J. K. Solberg, R. Gjengedal and A. O. Kluken: Mater. Sci. Technol., 11 (1995), 469.

23) C. Devadas, I. V. Samarasekera and E. B. Hawbolt: Metall. Trans. A, 22 (1991), 335.

24) W. J. Liu and M. G. Akben: Can. Metall. Q., 26 (1987), 145.

25) N. Radovic and D. Drobnjak: ISIJ Int., 39 (1999), 575.

26) B. Dutta and C. M. Sellars: Mater. Sci. Technol., 22 (1987), 1511.

27) S. F. Medina: Mater. Sci. Technol., 14 (1998), 217.

28) R. Abad, B. López and I. Gutierrez: Proc. of Int. Conf. Microalloying in Steels, ed. by J. M. Rodríguez-Ibabe et al., Trans. Tech. Publications, Switzerland, (1998), 167.

29) R. Priestner and C. Zhou: Advances in Hot Deformation Textures 
ISIJ International, Vol. 41 (2001), No. 11

and Microstructures, Edited by J. J. Jonas, T. R. Bieler and K. J. Bowman, TMS, Warrendale, PA, (1994).

30) A. I. Fernández: Ph. D. Univ. of Navarra, (2001).

31) K. B. Kang, O. Kwon, W. B. Lee and C. G. Park: Scripta Mater., 36 (1997), 1303.

32) W. P. Sun, M. Militzer, D. Q. Bai and J. J. Jonas: Proc. of Int. Conf. Recrystallization 92, eds. by M. Fuentes and J. Gil Sevillano., Mater. Sci. Forum, 113-115 (1993), 533.

33) O. Kwon and A. J. DeArdo: Acta Metall., 39 (1991), 529.
34) L. P. Karjalainen and J. S. Perttula: Proc. of 3th Int. Conf. on Recrystallization and Related Phenomena, Rex '96, ed. by T. R. McNelley, Monterey Institute of Advanced Studies, Monterey, (1996), 413.

35) S. F. Medina and J. E. Mancilla: ISIJ Int., 36 (1996), 1070.

36) P. D. Hodgson and R. K. Gibbs: ISIJ Int., 32 (1992), 1329.

37) R. K. Gibbs, R. Peterson and B. A. Parker: Proc. Int. Conf. Processing, Microstructure and Properties of Microalloyed Steels, ISS-AIME, Warrendale, PA, (1992), 201. 